\title{
COMPARING COMMERCIAL OPTICAL SENSORS FOR CROP MONITORING TASKS IN PRECISION VITICULTURE
}

\author{
Fabrizio Mazzetto, Aldo Calcante, Aira Mena
}

\section{Introduction}

Precision Viticulture (PV) may be defined as the methodologies that allow site-specific vineyard monitoring and management. It considers aspects of the monitoring and management of the spatial variations in productivity, in terms of quantity and quality, within the single vineyards [Lamb 2001a]. Unlike Precision Agriculture (PA), PV emphasises the need to monitor the activity performed compared to the need to use automation of the latter. Therefore in a PV system it is essential to make use of data gathering and automated recording, so that it may be used again in a decisional system supported by a Farm Information System (FIS). Thus the farms can develop three fundamental functions:

- monitoring, i.e. the gathering of field items data and parameters concerning production in its different contexts which are also useful in sustaining the decisions to control the operational activities (Different types of on-the farm monitoring proposed are those shown in Table 1 [Mazzetto 2006]);

- documentation, i.e. making information available even in variable conditions to meet any requests by the decision-making level of the farm, and anyone else working with certifications and control;

- operational control, i.e. providing procedures and giving predefined and controlled information to technicians, with little error margin, reaching the automated or semi automated execution of individual field items.

\section{State of the art}

Currently crop monitoring is the most studied application in PV systems. For this purpose, literature

Paper received 17.09.2007; accepted 13.01.2009

FAbrizio Mazzetto, associate professor; Aldo CALCANTE, researcher; Aira Mena, PhD student; Department of Agricultural Engineering, University of Milan; Via Celoria 2, 20133 Milan, Italy. E-mail: fabrizio.mazzetto@unimi.it proposes much work which is being done assessing aerial or satellite remote sensing.

Generally, multispectral acquisition systems collect images in few visible wavebands (green: $555-580 \mathrm{~nm}$; red: $665-700 \mathrm{~nm}$ ) and the near InfraRed (NIR: 740$900 \mathrm{~nm}$ ), significant to measure crop growth [Lamb 2000]. As it is known, it includes the elaboration of reflectance data, coming from multispectral optical surveys, in order to obtain virtual maps of vegetation

\begin{tabular}{|c|c|c|}
\hline $\begin{array}{c}\text { TYPE OF } \\
\text { MONITORING }\end{array}$ & DATA OBTAINED & $\begin{array}{c}\text { DATA } \\
\text { COLLECTING } \\
\text { TOOLS }\end{array}$ \\
\hline $\begin{array}{c}\text { Environmental } \\
\text { monitoring }\end{array}$ & $\begin{array}{l}\text { Physical, chemical, } \\
\text { pedological and climatic } \\
\text { parameters linked to the } \\
\text { environment where } \\
\text { production is carried out } \\
\text { (temperature, humidity, } \\
\text { solar radiation, soil } \\
\text { texture, soil pH, soil } \\
\text { nutrient content, etc.). }\end{array}$ & $\begin{array}{l}\text { Weather stations } \\
\text { (inside or outside of } \\
\text { the farm), sensors }\end{array}$ \\
\hline $\begin{array}{l}\text { Operational } \\
\text { monitoring }\end{array}$ & $\begin{array}{l}\text { Main farm production } \\
\text { data (farm management, } \\
\text { work methodologies, } \\
\text { control of farm input use- } \\
\text { quantity and/or volume- } \\
\text { work duration, etc.). }\end{array}$ & $\begin{array}{l}\text { Information Farm } \\
\text { books: solutions that } \\
\text { allow automatic } \\
\text { monitoring, partial or } \\
\text { complete, of } \\
\text { mechanized field } \\
\text { operations, giving } \\
\text { various types of } \\
\text { detailed information. }\end{array}$ \\
\hline $\begin{array}{c}\text { Crop } \\
\text { monitoring }\end{array}$ & $\begin{array}{l}\text { Information obtained } \\
\text { through crop } \\
\text { observations: } \\
\text { phenological phases, } \\
\text { nutritional state, plant } \\
\text { health, production } \\
\text { expectations, production } \\
\text { maps, etc. }\end{array}$ & $\begin{array}{l}\text { Different } \\
\text { technological } \\
\text { solutions still in the } \\
\text { research stage: } \\
\text { remote sensing } \\
\text { (RS), multispectral } \\
\text { image acquiring } \\
\text { systems, sensors able } \\
\text { to probe various } \\
\text { parameters of canopy } \\
\text { health and vigour. }\end{array}$ \\
\hline
\end{tabular}

TABLE 1 - Types of monitoring carried out on a farm. 
indices which are correlated in different ways to plant phytosanitary status. NDVI (Normalised Difference Vegetation Index) is one of the most known vegetation indices, often obtained from aerial RS data. It is used to identify different vegetative vigour level - especially in cover crops - on which production depends [Lamb 2001b]. It is also proven that in vine there is a significant correlation $\left(\mathrm{R}^{2}=0.74\right)$ between NDVI values and LAI $\left(\mathrm{m}^{2}\right.$ of leaf surface $\mathrm{x} \mathrm{m} \mathrm{m}^{2}$ of soil surface) and between NDVI and LAv ( $\mathrm{m}^{2}$ of leaf surface $\mathrm{x}$ plant) [Jhonson 2001]. LAv maps obtained from high resolution multispectral images, generated from IKONOS satellite, may be used to measure vine growth patterns or as a support for canopy management and irrigation scheduling [Jhonson 2003].

Remote sensing has also been employed successfully to identify vineyards subject to phylloxera (Daktulosphaira vitifoliae) infestations [Jhonson 1996]. Multispectral images has been used to obtain numerous vegetation indices to assess the relationship between their values and $\mathrm{a}$ and $\mathrm{b}$ chlorophyll content of Vitis vinifera $L$. at leaf and canopy level, to the aim of identifying chlorosis and monitoring crop physiological conditions [Zarco-Tejada 2005].

In spite of the many applications of remote sensing, data gathering strongly depends on climatic conditions, and using them is a complex matter. This is more evident in viticulture because of canopy architecture, presence of soil or grass in the inter-row space, and the shadowing caused by the rows [Stamatiadis 2007]. In fact, together with remote sensing, research has been carried out to develop crop monitoring tools using so called "ground sensing" technologies. These rather complex systems, were developed for use in a controlled environment to study the plant-environment interaction [Kacira 2001]. In order to be used on the field, studies were carried out to develop NIR sensors for use in herbicide applications capable of differentiating between live vegetation materials and other sublayers (soil, crop residues) [Shearer 1996]. Tools of this type are very useful as they can be used on a tractor, to monitor and diagnose, in real time, the state of the plants to permit agrochemicals and fertilizer variable rate application (VRA). The use of optical sensors for fertilizer VRA was introduced in the United States by Stone et al. [Stone 1996; Stone 1995] and in Germany by Heege and Reusch [Heege 1996]. Currently there are several devices commercially available that determine NDVI in real time. As an example, the GreenSeeker RT100 (NTech Industries) and the Crop Circle (Holland Scientific) are optical sensors usually employed in nitrogen fertilization management in corn crops [Shaver 2007].In particular the GreenSeeker RT100 is the result of studies carried out by Oklahoma State University (OSU) with the collaboration of NTech Industries, Inc. (Ukiah, California). A first prototype was realized in 1996. It was made up of a passive sunlight illuminated optical sensor, and a VRT applicator [Crummet 1996; Kimberlin 1996]. This device can check the crop and apply in real time the correct amount of nitrogenous liquid fertilizer based on a grid of 0,75 x $0,75 \mathrm{~m}$. In 1997 , OSU came up with a computerized active optical sensor, in order to develop a system for VRA of nitrogen, according to specific fertilization strategies. This device led to the development of the GreenSeeker which is capable of delivering in real time vegetation indices NDVI and Red/NIR, and it is also being used in farms to manage cover crops fertilization such as wheat, corn and sugar beet. Recently, its application in viticulture is being studied, to characterized vine vegetation vigour spatial distribution [Goutouly 2006; Mazzetto 2007].

This work is studying the feasibility of integrating remote sensing information with that coming from ground sensing technologies that can be used in vineyard directly. This should overcome the various technical, economic and managerial problems, which limit the use of remote sensing technologies in Italian vineyards made up mostly of small/medium size farms. To this aim, GreenSeeker was tested in a greenhouse on Cabernet Sauvignon vines characterized by different phases of plant health. The objective was to assess the amount of data recorded by said tool, usually used on cover crops (corn) for mobile observations from the tractor, and compare them to the images acquired from a multispectral digital camera, the Tetracam ADC, used in remote sensing in agriculture, too [Haitao 2007; Thomson 2007].

\section{Vegetation indices}

As it is well known, vegetation indices obtained from multispectral optical relieves are the result of the algebraic combination of the reflectance $\left(R_{i}\right)$ of the vegetation in the different $\mathrm{i}$-esimal wavebands of the spectrum. In NDVI and Red/NIR indices, both describing photosynthetic potential, red and Near Infrared (NIR) wavebands are always included. The two indices derive from the well known algebraic expression [Chen 1996; Jordan 1969; Rouse 1974]:

$$
\begin{gathered}
\text { Red } / N I R=\frac{R_{\text {SED }}}{R_{\text {NDR }}} \\
N D V I=\frac{\left(R_{\text {NW }}-R_{\text {SED }}\right)}{\left(R_{\mathrm{XW}}+R_{\text {RED }}\right)}
\end{gathered}
$$

Both the two indices are correlated to the amount of plant biomass per unit of leaf surface (LAI), therefore to the vigour of the crop. They allow a link between chlorophyll absorption in the red and the reflection in the near IR where it is largely influenced by leaf structure. Red/NIR is more often used to classify vegetation against the soil, but it seems to be also linked to the physiological status of plant. It always shows positive values, increases indicate a worsening of vegetation conditions. This index presents some problems due to shaded areas, and to the difficulty to establish a threshold value discriminating between 
soil and vegetation and even more so between healthy and unhealthy vegetation [Zarco-Tejada 2005]. NDVI value is between -1 and +1 , so it is easier to understand and use than Red/NIR. When used in agriculture, NDVI values vary from a minimum of 0.1 to 0.3 for a bare soil or with little grass, reaching an asymptotic saturation value around $0.8-0.9$ for vegetation with LAI superior to 5 . NDVI can be considered an improvement of Red/NIR index because through the normalisation it eliminates disturbance effects of reflectance that occur in the broad band between red and NIR [Zarco-Tejada 2005]. For the manner in which the two indices are defined, NDVI $(y)$ and $\operatorname{Red} /$ NIR $(x)$ are univocally linked by the following algebraic relation (Figure 1):

$$
y=\frac{(1-x)}{(1+x)}
$$

Therefore simultaneous use of the two indices may be redundant, as they describe the same situation using different values, though they are univocally related. The optical results carried out on the same crop, give for both indices, a typical bimodal frequency distribution as in the example described in Figure 2. In the case of canopy analysis, the population observed with the highest frequency is classified as "vegetation tissue" (normally with NDVI $>0.30$ ). All the rest is classified as "background". So, the automatic identification of vegetation tissue requires the calculation of the NDVI value which discriminates between the two data populations.

\section{Materials and methods}

The aim of this work is to verify GreenSeeker performance when it is used in situations different from

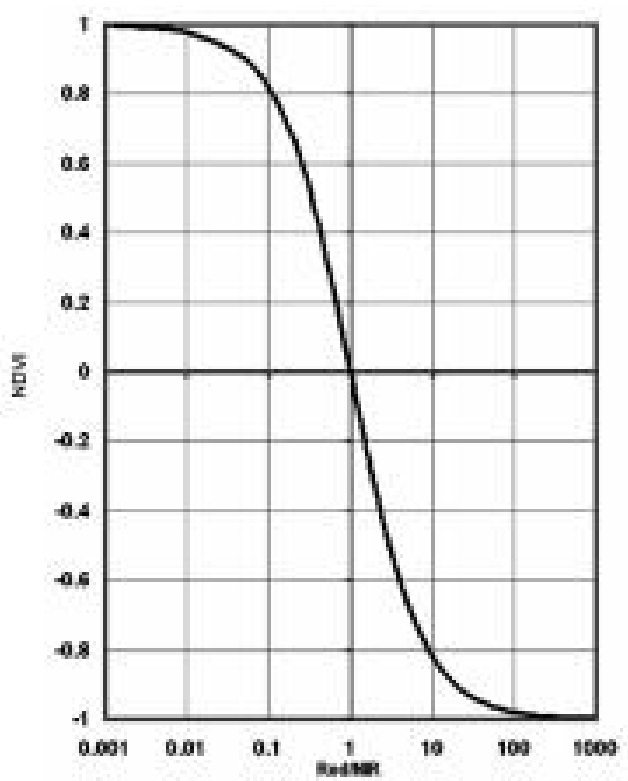

Fig. 1 - Theoretical curve obtained through the application of the mathematic relation (3) between Red/NIR and NDVI values.. those it was designed for. In this case, it is used in monitoring vegetation no longer used as cover crop, but planted in vertical rows with a background different from soil.

The tools observed are:

1. "GreenSeeker RT100" (Ntech Industries, Inc., Ukiah, California);

2. "Tetracam ADC" multispectral digital camera (Tetracam, Inc., USA).

The first one is a mobile system with an active lighting optical sensor made up of an electroluminescent diode, LED, which emits a high intensity light $660+/-10 \mathrm{~nm}$ in red and $770+/-15 \mathrm{~nm}$ NIR wavebands. LED pulses at $100 \mathrm{~Hz}$ frequency with an average reading of $10 \mathrm{~Hz}$. The light is reflected by the leaves and it is captured by a silicon photodiode positioned in the front of the sensor. Electronic filters remove all background illumination. In this way, GreenSeeker gives back the index values NDVI and $\mathrm{Red} / \mathrm{NIR}$ in real time, directly. The GreenSeeker calculates Red/NIR values of -0.9 in correspondence of no-vegetative elements. This fact, which is not marked by the producer, can be considered as a threshold between Red/NIR values referred to vegetate and no-vegetate zones. In the present work, this characteristic is not considered because tests were carried out in a greenhouse on single plants.

Tetracam is designed for remote sensing application and it has been used to detect vegetation canopy reflectance. The ADC is a single CMOS sensor digital
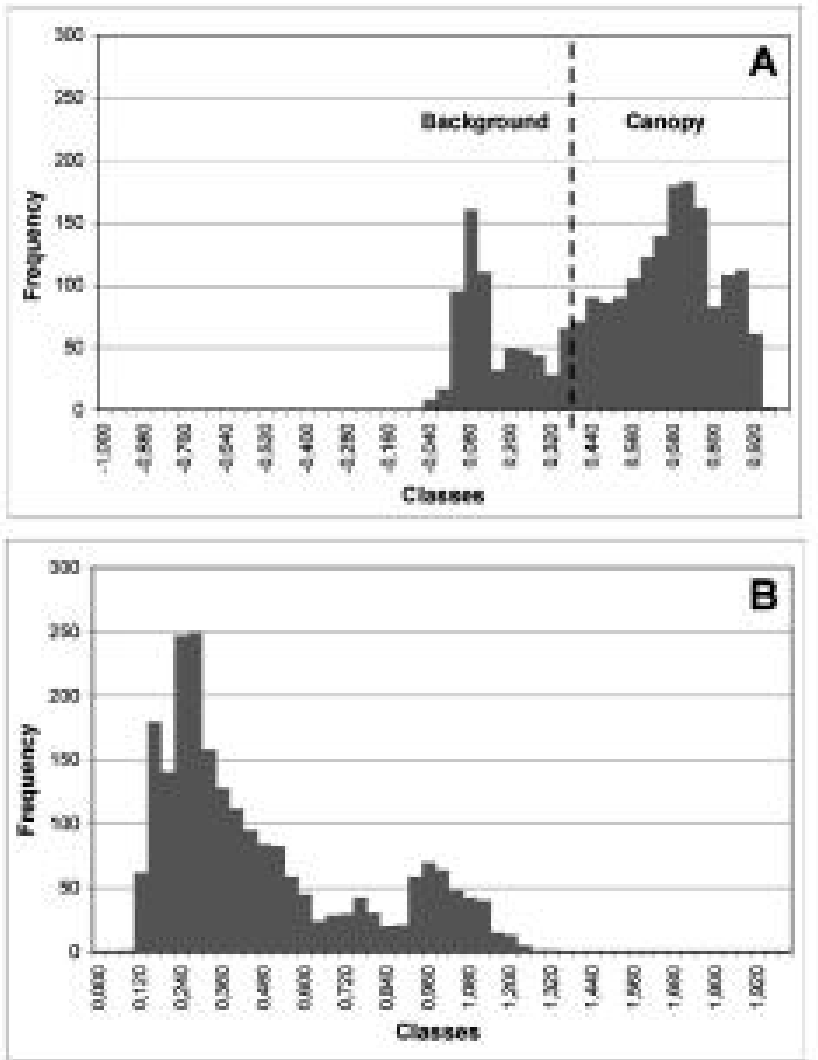

Fig. 2 - Bimodal frequency distribution of NDVI (A) and Red/NIR (B) values collected on vines located in the greenhouse. 
camera specifically designed for light wavelengths in green $(520-570 \mathrm{~nm})$, red $(635-667 \mathrm{~nm})$ and NIR (835 - $870 \mathrm{~nm})$ bands. A longpass filter was applied for selecting near-infrared radiation and excluding blue light. The camera provides false-colour images suitable for later derivation of several vegetation indices. The image size is 2048 x 1536 pixels $(3.2$ Mpixel) 1/2" optical format. Images are stored to CompactFlash in Tetracam DCM lossless format. Time exposure was set to $0.5 \mathrm{~ms}$ during tests.

The camera was preliminary calibrated taking an image of a teflon white tag under the same test conditions. The image was then used to teach the application software about the sunlight spectrum. The ratio of red/NIR or green/NIR is then applied as an offset to the calculation of the various vegetation indices. Because of its optimal characteristics Tetracam was used as a tester in this study.

Tests were carried out in a greenhouse where a row was made up of Cabernet Sauvignon vines, grown in pots, positioned at $0.28 \mathrm{~m}$ one from the other; in this way conditions of a canopy vertical development typical of rows in vineyard have been created. A black sheet normally used for mulching was used as background. Plants were divided into three parcels and went through different phytosanitary treatment:

- parcel 1: plants inoculated with Plasmopara viticola;

- parcel 2: stress-free plants;

- parcel 3: plants that did not go through any phytosanitary treatment, which spontaneously developed oidium.

A metallic rail gauge $(6 \mathrm{~m}$ long) was placed in front of the plants on which a mobile carrier runs. This allows a longitudinal and a transversal movement (both manual) of the GreenSeeker, respectively along the row and along the vegetation wall. The mobile carrier guarantees the repetition of the measurements in the same position during the time; so the observation of vegetation indices values evolution on the same canopy portion is possible. During these tests GreenSeeker was made to stop in front of each plant for 5 seconds. The tool is placed about $0.60 \mathrm{~m}$ from the plants; at this distance it projects a beam of light of about 0.7 and $0.01 \mathrm{~m}$ in length and width respectively (Figure 3). Each plant was tested at three different heights: $0.55 \mathrm{~m}, 0.90 \mathrm{~m}$ and $1.25 \mathrm{~m}$. Tests were carried out every day from May, 17 to June, 30 2006 for a total of 19 day-trials. Tests were always carried out about at the same time in order to maintain greenhouse climatic conditions the most stable as possible. GreenSeeker measurements were not repeated during the same day.

GreenSeeker observations were then compared to the data obtained with the multispectral camera, in order to compare information coming from GreenSeeker with the evaluation of vegetation indices coming from conventional approaches of RS. Close up pictures of the individual GreenSeeker analysis were taken according to perpendicular view of the vegetation wall (focused on the stem of the plant in an area of $0.7 \times 0.01 \mathrm{~m})$. The portion of the picture correspondent to the leaf area investigated by the GreenSeeker was manually selected. These images were then processed using a specific software developed in the research: LSODA ver. 1.0-06 by which the average NDVI value was calculated, taking into account all the single pixel values included in the analysed area. In particular, LSODA allows a step-by-step virtual analysis of canopy damage through the application of software filters to NIR images. Filters allow vegetation identification and suffering area detection. Through an iterative algorithm pixels referred to background are removed, then NDVI is calculated on each pixels referred to vegetation and its mean value is computed for each picture. Thus we were able to determine:

- NDVI comparison given by the two tools used on the same portions of vegetation with different vegetation vigour due to different phytosanitary treatments;

- analysis over a period of time of NDVI values referred to the various parcels.

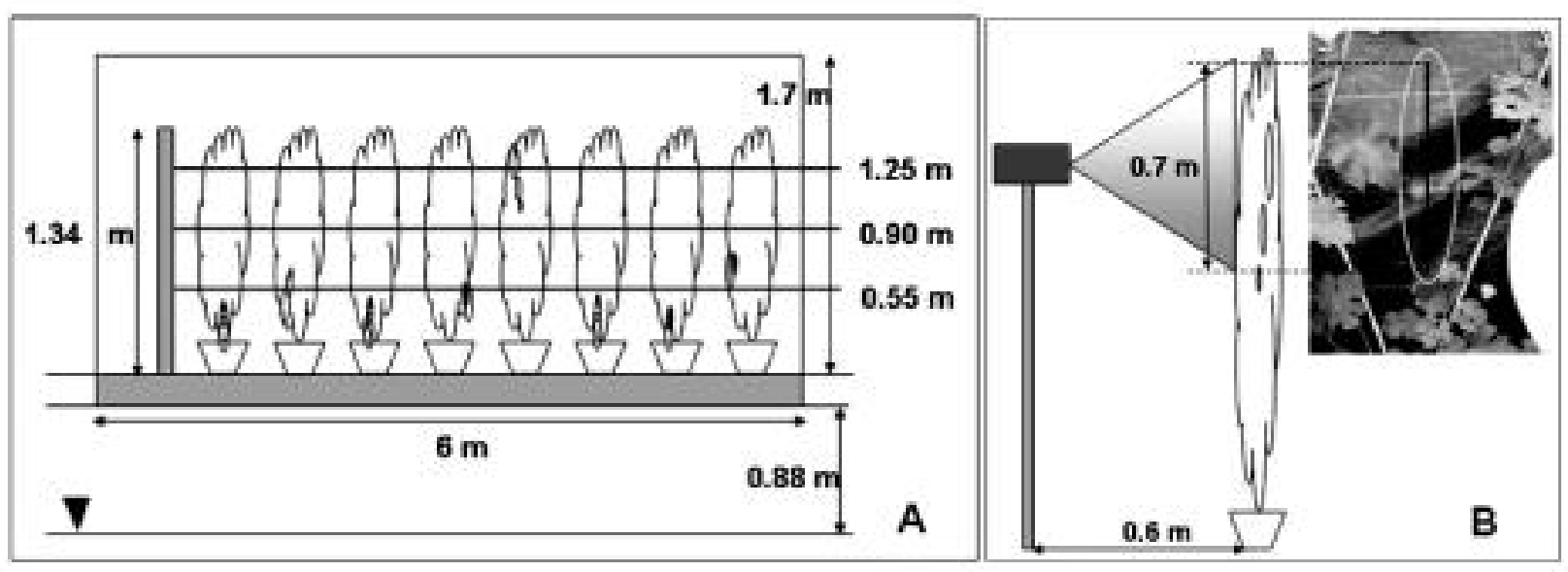

Fig. 3 - Plants disposition in the greenhouse during the tests (A) and GreenSeeker positioning regarding vegetation wall (B). 


\section{Results and discussion}

Data used in the comparison between GreenSeeker and Tetracam were taken from greenhouse tests results, so they refer to both different plants and days. The graph in Figure 4 shows that the two tools are very closely linked $\left(\mathrm{R}^{2}=0.97, \mathrm{RMSE}=0.061\right)$, and from the graphic analysis we notice how the linear regression is overlapped to the bisecting line in the first and third quadrant of the Cartesian graph (the expected result)

The significance of the result is confirmed by the application of Student's two-tailed t-test for the mean of two coupled population (significance $\alpha=0.05 ; \mathrm{t}=$ 0.89 ; critical $t=1.99$ ), and by the verification of the intervals confidence of the regression angular coefficient ( $\beta)(\beta=0.97 ; t=49.9)$. Therefore, it can be asserted that the error occurred is accidental and it is due to:

- the different behaviour of the two tasks (the

GreenSeeker doesn't need any setting, whereas

Tetracam needs a manual setting);

- measurement errors;

- imprecisions in the manual selection of images acquired with the multispectral camera, regarding the real area investigated by the GreenSeeker.

Data analysis carried out within single parcels shows a high correlation between NDVI obtained through the two different tools, too (Table 2). In this case an averaged NDVI value was computed for each parcel and each day of test at $0.90 \mathrm{~m}$ in height.

Figure 5 demonstrates the graph which shows one single Cabernet Sauvignon plant affected by oidium during the tests. The infection was rather serious and caused the plant withering; so it was possible to monitor NDVI over a period of time starting from an excellent vegetation vigour up to the death of the plant. The graph in Figure 5 shows the NDVI over a period

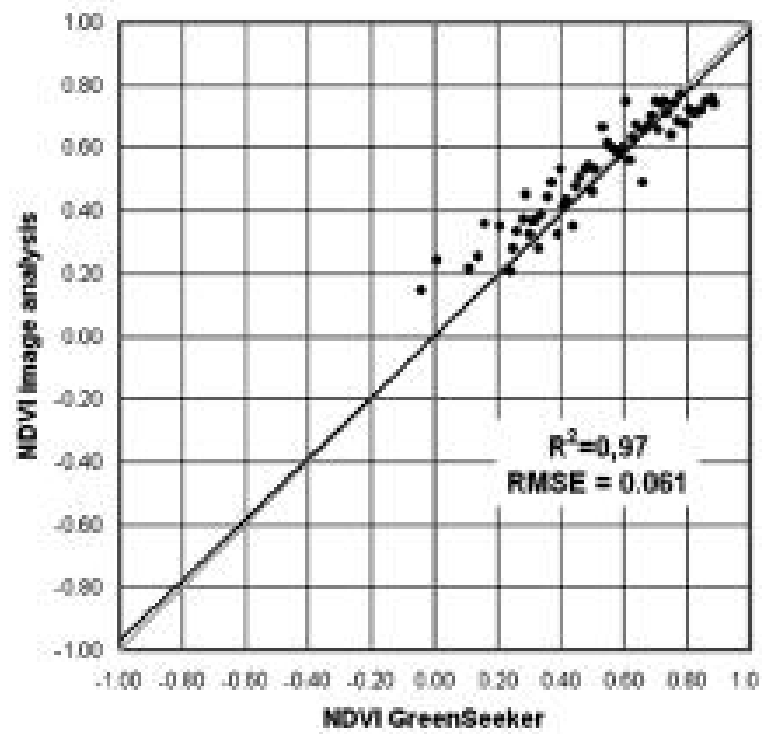

Fig. 4 - Correlation between NDVI values obtained by GreenSeeker and those derived from multispectral image analysis acquired by Tetracam. of time obtained respectively by GreenSeeker and multispectral images. In both cases we can see a decrease of NDVI due to the worsening health of the plant. Results obtained confirm the validity of the GreenSeeker vegetation indices, which can also be applied in vine monitoring. As a result, ordinary kriging was applied to NDVI values, measured by GreenSeeker, in order to represent them for the canopy vertically development. Images in Figure 6 illustrate NDVI data for two days of tests in which the vegetation wall shows very different vigour conditions. The scale used is within a minimum of -0.3 and a maximum of 0.9 divided in classes of size 0.05 ; the threshold value applied is 0.4 . Visual analysis of vegetation vigour maps compared with RGB photos confirm a superior qualitative link between GreenSeeker observations and the real situation of the plant.

\begin{tabular}{|l|c|c|c|c|}
\hline & $\mathbf{R}^{\mathbf{2}}$ & RMSE & Mean & St. Dev. \\
\hline Parcel 1 & 0.99 & 0.044 & 0.645 & 0.140 \\
\hline Parcel 2 & 0.99 & 0.039 & 0.750 & 0.071 \\
\hline Parcel 3 & 0.98 & 0.055 & 0.389 & 0.073 \\
\hline
\end{tabular}

TABle 2 - R-squared coefficients, Root Mean Squared Error, Mean and Standard Deviation of NDVI values obtained by GreenSeeker and those derived from multispectral image analysis acquired by Tetracam in each parcel.

\section{Conclusions}

The objective of this work was to test an optical technology, normally used on cover crop, to assess its validity and its possible use within ground sensing crop monitoring in viticulture. Results obtained from GreenSeeker were more than acceptable, in spite of the fact that it was used in conditions different from those it was normally used. A comparison between NDVI data obtained by GreenSeeker and those derived from a multispectral image analysis, used as a reference, was positive; this was confirmed by the excellent correlation obtained $\left(\mathrm{R}^{2}=0.97\right)$. In addition, GreenSeeker performed very well with regards to artificially created and spontaneous pathological stress in plants, demonstrating a quick adjustment of NDVI to phytosanitary conditions and to vine vigour. Vigour vegetation maps obtained through kriging show, though on a small scale, how useful GreenSeeker is in viticulture crop monitoring. In fact, if tests in vineyard will confirm the satisfying results obtained in greenhouse, these maps produced at scale of field could be an effective managerial tool to detect vineyard areas featured by different vigour levels, thus addressing scouting tasks to these critical areas. Finally, GreenSeeker is more flexible than remote sensing because:

- it seems not influenced by climatic conditions (cloud cover) and sunlight because it implements its own light source; 


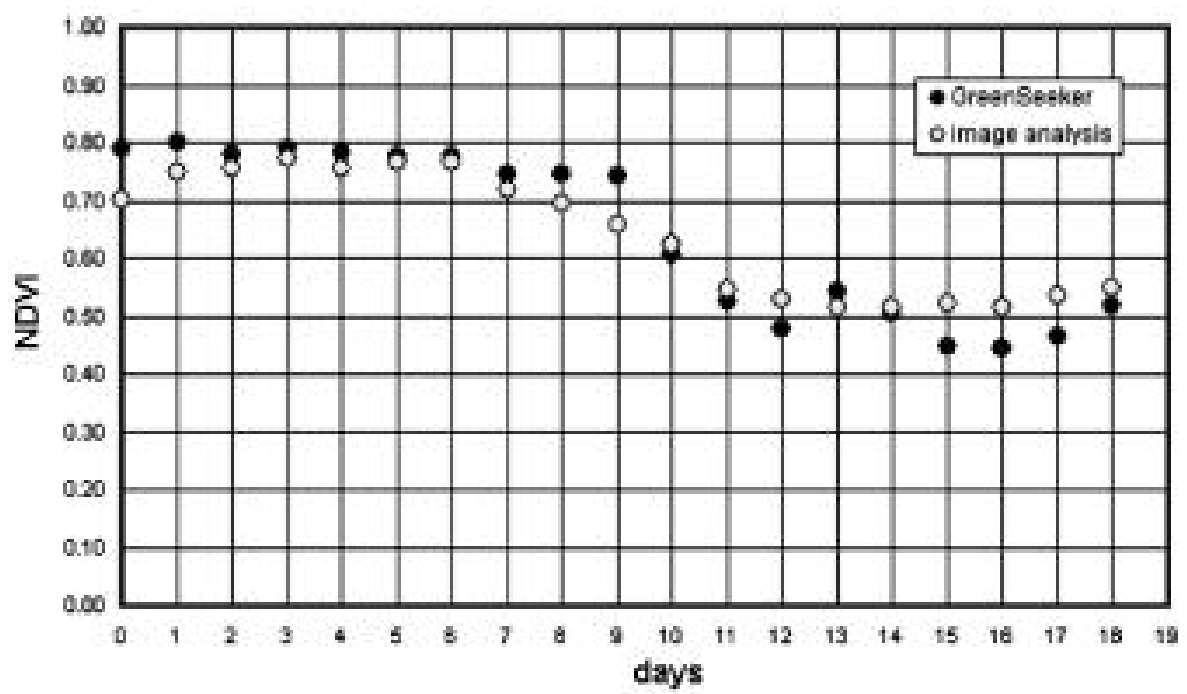

Fig. 5 - NDVI temporal course referred to a single vine infected by oidium.

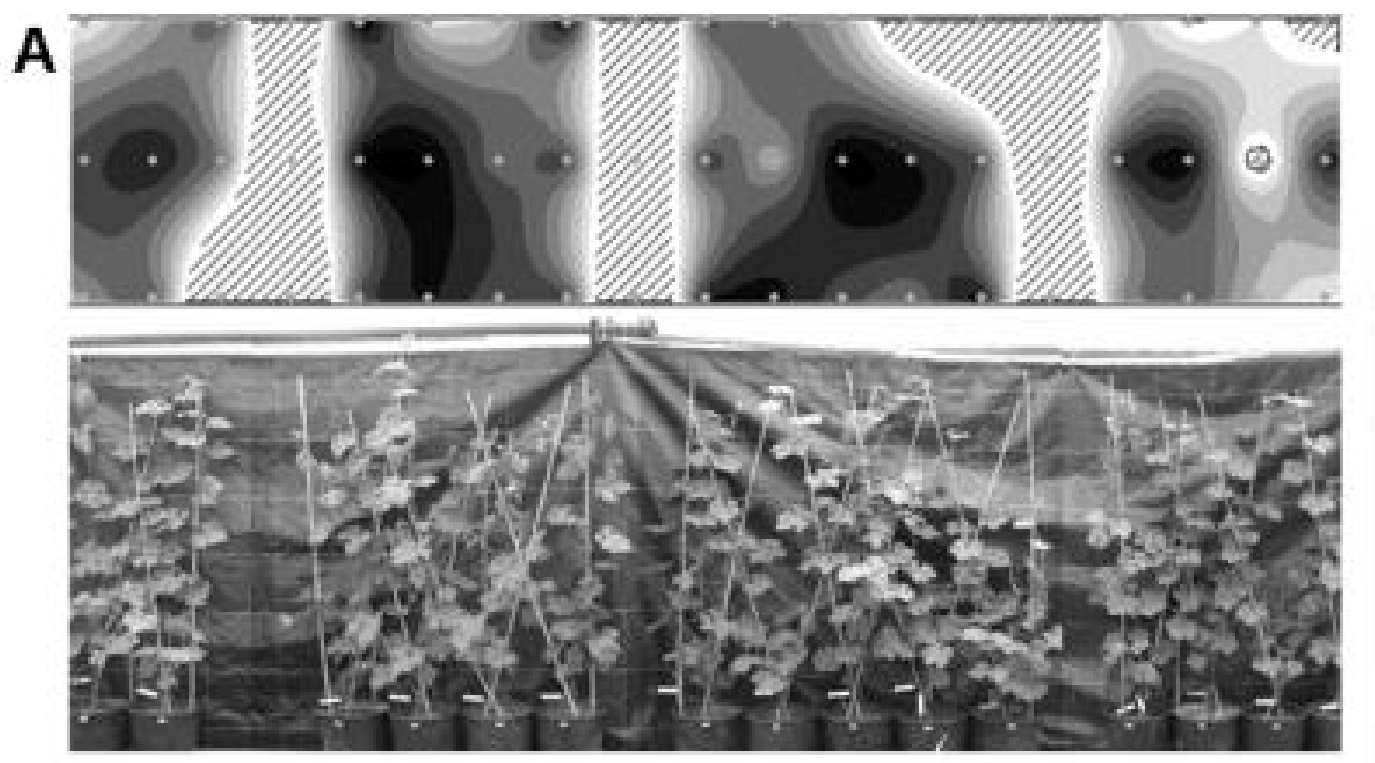

B
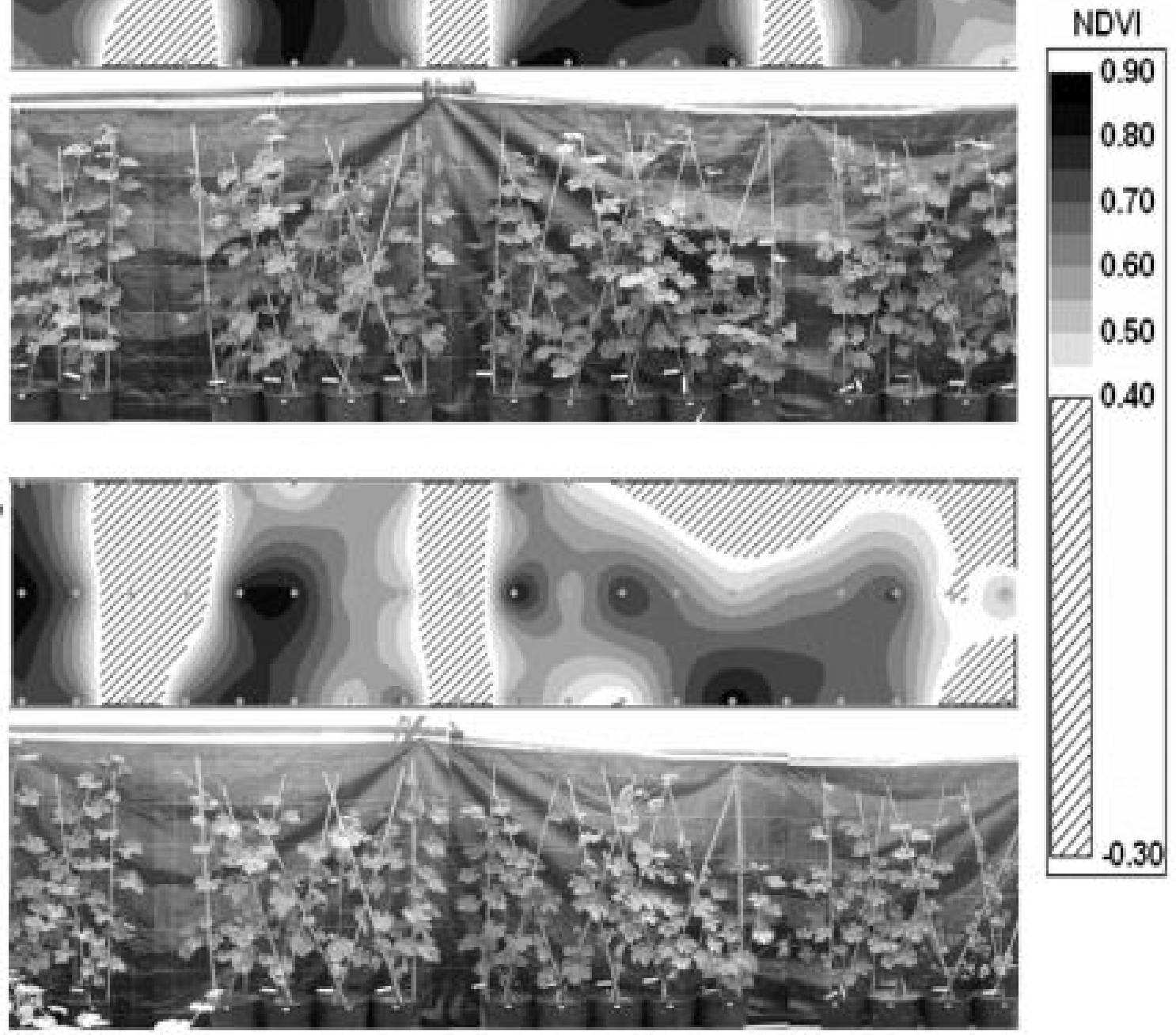

Fig. 6 - Kriging representation of NDVI values compared to RGB photo. Pictures referred to data collected at the beginning (A) and at the end (B) of the test. 
- it gives more detailed information;

- it can be used at any time;

- it delivers indices vegetation values in real time;

- if used simultaneously with the usual mechanized operations (as tractor-mounted tool), it saves farm workers' time which would otherwise be used to monitor the crop;

- it is a commercial available sensor requiring not prohibitive investments.

All considered, this tools is highly suitable to be applied in Precision Viticulture as "ground sensing" device for crop monitoring. However further tests will be necessary to evaluate GreenSeeker use in vineyards and its actual independence of light condition. To this aim a mobile laboratory is at the research stage, which implements a couple of GreenSeeker in order to monitoring both sides of the rows. In this case, even if an economic analysis is still necessary, considering the cost of the two sensors and of an appropriate data-logger comprehensive of high accuracy GPS, the mobile lab final cost will be realistically supported by PA service companies.

\section{References}

CHEN J., Evaluation of vegetation indices and modified simple ratio for boreal applications. Canadian Journal of Remote Sensing, 1996, 22(3), 229-242.

CRUMmet D., On-the-fly live plant analysis. Oklahoma Farmer Stockman. Farm Progress Publ. Co., Stillwater, OK., 1996, 109(2), 8-9.

Goutouly J.P., Drissi R., Forget D., Gaudillère J.P., Characterization Of Vine Vigour By Ground Based NDVI Measurements. Proceedings of VIth International Terroir Congress, 2006, 3-5 Luglio, Bordeaux, 237-241.

Haitao X., Lei T., An Autonomous Helicopter System for Aerial Image Collection. Paper Proc. 071136, 2007 ASABE Annual International Meeting, 2007, Minneapolis, June 17-20.

Heege J.J., Reusch S., Sensor for on the go control of site specific nitrogen top dressing. ASAE Paper No. 961018. ASAE St. Joseph, MI , 1996, 49085-9659.

Johnson L., Lobitz B., Armstrong R., BALdy R., Weber E., DeBenedictis J., Bosch D., Airborne imaging aids vineyard canopy evaluation. California Agriculture, 1996, 50(4), 14-18.

Johnson L., Roczen D., Youkhana S., Vineyard canopy density mapping with IKONOS satellite imagery. Proc. of $3^{\text {rd }}$ International Conference on Geospatial Information in Agriculture and Forestry, 2001 Denver, Colorado (ERIM International INC.: Ann Arbor, MI, USA). In Press.

Johnson L.F., Roczen D.E., Youkhana S.K., NemanI R.R., Bosch D.F., Mapping vineyard leaf area with multispectral satellite imagery. Computers and Electronics in Agriculture, 2003, 38(1), 33-44.

JORDAN C.F., Derivation of leaf area index from quality of light on the forest floor. Ecology, 1969, 50, 663-666.

KACIRA M., Ling P.P., Design and Development of an Automated and Non-Contact Sensing System for Continous
Monitoring of Plant Health and Growth. Transaction of the ASAE, 2001, 44(4), 989-996.

KIMBERLIN K., OSU demonstrates sensor-based farming. Rancher Farmer New. Maverick Publ. \& Design, Inc. Norman, OK., 1996, 2(3), 6-7.

LAmb D.W., Bramley R.G.V., Managing and monitoring spatial variability in vineyard productivity. Natural Resource Management, 2001a, 4(1), 25-30.

Lamb D.W, Hall A., Louis J., Airborne remote sensing of vines for canopy variability and productivity. Australian Grapegrower \& Winemaker, 2001b, 449a, 89-92.

LAMB D.W., The use of qualitative airborne multispectral imaging for managing agricultural crops - a case study in south-eastern Australia. Australian Journal of Experimental Agriculture, 2000, 40(5), 725-738.

Mazzetto F., Calcante A., Mena A., Comparing commercial optical sensors for crop monitoring tasks in Precision Viticulture, Poster Paper Proc. Precision Agriculture '07, 2007, Skiathos (GR), 3-6 June.

MAZzETTO F., La centralità dei sistemi informativi aziendali tra management informatizzato e agricoltura di precisione (The centrality of farm information systems and computerized management in precision agriculture). Proc. of Workshop CITIMAP Telerilevamento per un'agricoltura sostenibile, 2006, Piacenza, 20 Aprile

Rouse J.W., HaAs R.H., Schell J.A., DeERING D.W., HaRLAN J.C., Monitoring the vernal advancements and retrogradation of natural vegetation. NASA/GSFC final report. MD USA Greenbelt, 1974, $371 \mathrm{pp}$.

Shaver T.M., Westfall D.G., Khosla R., Comparison of three active hand-held NDVI (normalized difference vegetation index) remote sensors for nitrogen management in corn. Paper Proc. of Precision Agriculture '07, 2007, Skiathos (GR), 3-6 June.

Shearer S.A., Thomasson J. A., McNeil S.G., Filter Selection for NIR Sensing of Plant and Soil Materials. Transaction of the ASAE, 1996, 39(3), 1209-1214.

Stamatiadis S., Taskos D., Tsadila E., Christofides C., TSADIlas C., SCHEPERS J.S., Proximal remote sensing: Technological advances and applications in vineyards, Poster Paper Proceedings of Precision Agriculture '07, 2007, Skiathos (GR), 3-6 June.

Stone M.L., Marvin L., Solie J.B., Whitney R.W., Raun W.R., LEESE H.L., Sensors for detection of nitrogen in winter wheat. SAE Technical paper series. SAE Paper No. 961757. SAE, 1996, Warrendale PA.

Stone M.L., Solie J.B., Raun W.R., Taylor S.L., Ringer J.D., WhitNeY R.W., Use of spectral radiance for correcting in-season fertilizer nitrogen deficiencies in winter wheat. ASAE Paper AETC 95133. Am. Soc. Agr. Engr St. Joseph, MI, 1995, 9085-9659.

Thomson S.J., SMIth L.A., Hanks J.E., An Instrumentation Platform and GPS Positioning Latency Issues for Remote Sensing on Agricultural Aircraft. Transaction of the ASABE, 2007, 50(1), 13-21.

Zarco-Tejada P.J., Berjón A., LóPez-Lozano R., Miller J.R., Martín P., Cachorro V., González M.R., De Frutos A., Assessing vineyard condition with hyperspectral indices: Leaf and canopy reflectance simulation in a row-structured discontinuous canopy. Remote Sensing of Environment, 2005, 99(3), 271-287. 


\section{SUMMARY}

The emergence of precision agriculture technologies and an increasing demand for higher quality grape products has led to a growing interest in Precision Viticulture. Actually, cultural monitoring is the most important application in PV systems: it requires specific technologies able to investigate the cultural conditions. To this aim, typically remote sensing surveys are adopted. These, anyhow, involve technical, economical and organisational barriers hampering a wide diffusion of their application. In order to overcome these problems, it would be necessary to substitute and/or integrate remote sensing information with alternative ground sensing technologies, to be employed directly inside the vineyard. This paper considers a commercial optical sensor, the GreenSeeker, useful in ground sensing surveys, and it compares its performances in monitoring vine with results obtained by a multispectral digital camera used as a tester.

The experimentation was carried out in a green- house, on an artificial row including 15 grapevines (Cabernet Sauvignon variety). In front of the row, it was fixed a metallic rail gauge in order to permit a longitudinal movement of the Greenseeker sensor. Each plant was investigated at three different heights with a 5 s data time acquisition. Simultaneously, photos of the same grapevine were took by a multispectral digital camera, in order to obtain NDVI values through image analysis. The multispectral digital camera, normally used for remote sensing survey in agriculture, was considered as a test.

Results demonstrate a strength correlation $\left(\mathrm{R}^{2}=\right.$ 0.97 ) between the NDVI values measured through the two methods. This shows the same behaviour of the two tools, according to crop vigour and stress conditions induced into the plants. Consequently the GreenSeeker can be considered as a suitable solution for cultural monitoring in viticulture.

Keywords: ground sensing, optical sensor, precision viticulture. 